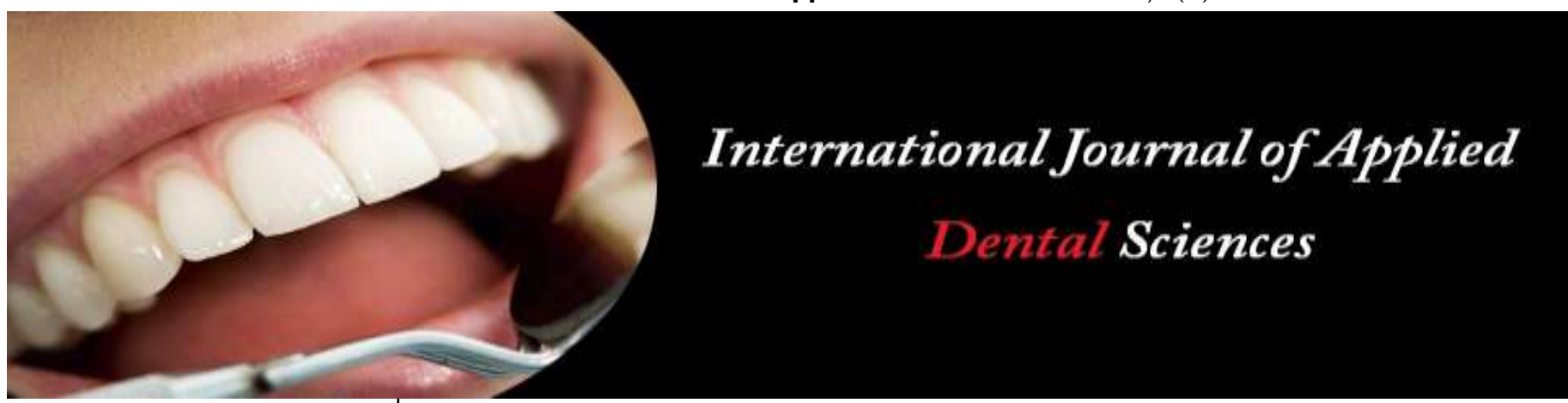

ISSN Print: 2394-7489

ISSN Online: 2394-7497

IJADS 2021; 7(1): 367-369

(C) 2021 IJADS

www.oraljournal.com

Received: 28-11-2020

Accepted: 30-12-2020

Dr. Isha Rastogi

Mds Assistant Professor (AP) in

Mims, Uttar Pradesh, India
Corresponding Author: Dr. Isha Rastogi

Mds Assistant Professor (AP) in Mims, Uttar Pradesh, India

\section{Oral health care in Indian population}

\author{
Dr. Isha Rastogi \\ DOI: https://doi.org/10.22271/oral.2021.v7.i1e.1157
}

\section{Abstract}

Introduction: Oral health care is essential for well-being of an individual. Loss of teeth or edentulism is a common problem in everyone. As age advances, we face many body and oral problems.

Aim and Objectives: To assess edentulism in population.

Material and Methods: 5oo subjects above 20 years were chosen.

Results: People have teeth loss but they are unattended.

Discussion: Patients know they have teeth loss and few are knowing about how to deal with it.

Conclusion: Dental care and education should be provided to all. Keywords- oral, loss, teeth.

Keywords: oral health care, Indian population, edentulism

\section{Introduction}

Teeth and oral health care are vital for all aspects of life. They provide functions of chewing, speech and esthetics. Edentulism is the state of being edentulous or without natural teeth ${ }^{[1]}$. Edentulism is a devastating and irreversible condition and is described as the final marker of disease burden for oral health ${ }^{[2]}$.

Awareness is important in determining ${ }^{[1]}$ and maintaining overall oral health of a person ${ }^{[3]}$. We often neglect our oral health thinking it to be of little or no use. The loss of teeth affects various vital functions as mastication, phonetics, esthetics, dietary intake and nutrition status. It compromises and affects general health ${ }^{[4]}$. It is high time we give importance to teeth and dentition. .We have heard and seen that epidemiological surveys have been conducted in India and abroad on dental caries and periodontal problems but Prosthodontic field has never shown any interest to scholars ${ }^{[7]}$. Last (1988) defined ${ }^{[8]}$ epidemiology as "the study of the distribution and determinants of health-related status or events in specified populations and the application of the study to control health problems ${ }^{[8]}$.

Aim: using questionnaire and basic tools we assess edentulism

Objectives: To evaluate edentulism in rural and urban populations

Clinical relevance: population has teeth loss but they do not pay much emphasis on this.

Material and methods-villages surrounding hospital with 500 subjects above 20 years half from village and half from city in 2 months were studied.

Personal details were asked and recorded like in normal conversation.

Results: data was noted as-

Gender: Males 258 females 242

Edentulism- no missing 187, <5 missing 189, 5-15 missing 63, >15 completely edentulous 61 .

Causes: Dental caries 140, periodontitis 61, trauma 35, dental caries and periodontitis 77. 


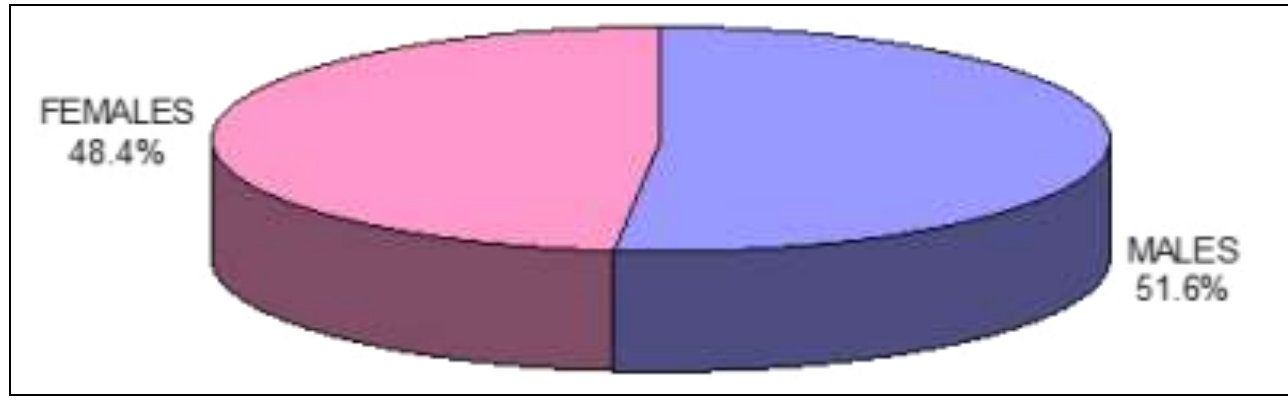

Fig 1: Gender

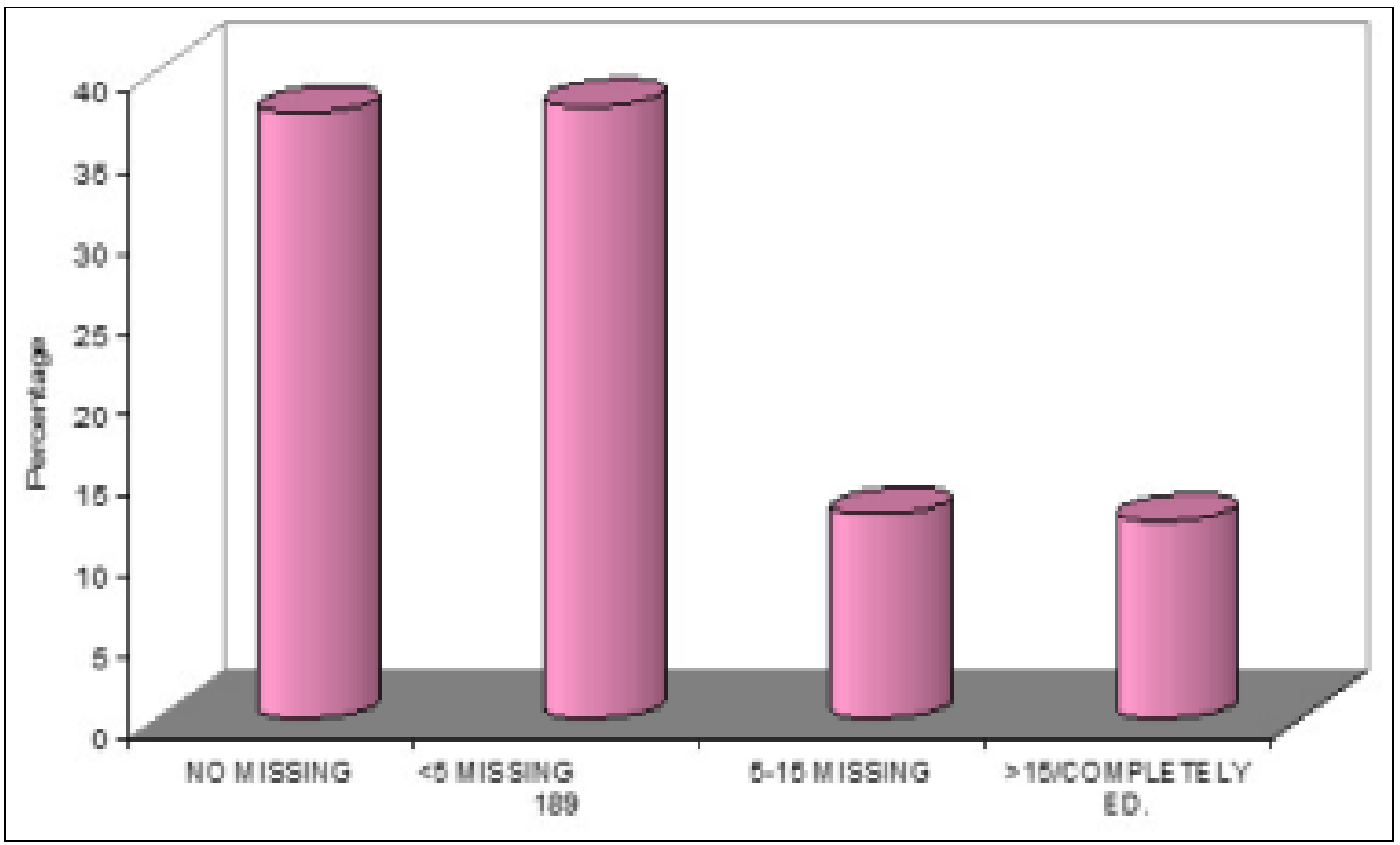

Fig 2: Edentulism

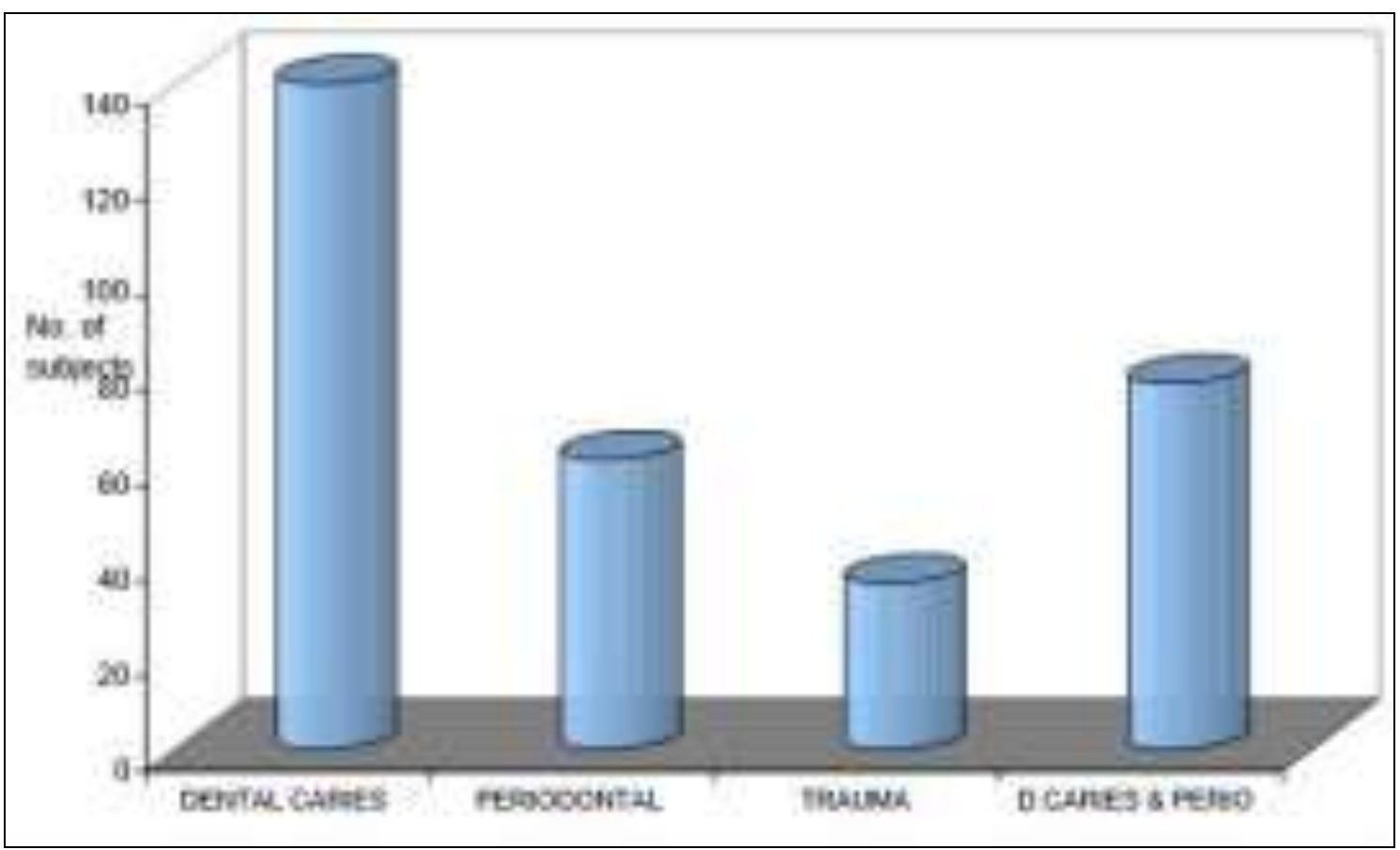

Fig 3: Cause

\section{Discussion}

We see that more males have been enrolled in study. Various dental conditions arise because of caries, periodontal diseases and trauma. Despite the development of curative and preventive dental care in the last decade, edentulism continues to be a challenging problem to healthcare provider ${ }^{[5]}$. Low 
income and education level, poorer oral health and reduced general health correlated with the incidence of tooth loss. Higher periodontal disease marks perceived poor dental health, the perceived need for extractions, history of smoking and low ascorbic acid intake ${ }^{[9]}$.

\section{Conclusion}

Tooth loss especially complete loss or edentulism is equivalent to dental death ${ }^{[10]}$.

Khazaei concluded that the total rate of edentulism is believed to be on a steady decrease in developed countries while in the developing countries the reverse is seen ${ }^{[6]}$. Our citizens need to be encouraged and oral health in all should be emphasized.

\section{Reference}

1. Adam RZ. DO CD improve qol pof patients? University of Western Cape 2006.

2. Cunha Cruz et al. Secular trends in socioeconomic disparities in edentulism. J Dent Res 2007;86:131-6.

3. Jyoti Nadgere, Anita Gala-Doshi, Sumana Kishore. An Evaluation of Prosthetic Status and Prosthetic Need amongst people living in and around Panvel, NaviMumbai-A Survey. International Journal of Prosthetic Dentistry 2010:1(1):6-9.

4. Suresh S, Swati Sharma. A clinical survey to determine the awareness and preference needs of a complete denture among complete edentulous patients. J Int Oral Health 2010;2(3):65-69.

5. Rafee MA. The epidemiology of edentulism and associated factors. J Family Med Prim care 2020;9:18413.

6. Khazaei S et al. Edentulism and tooth loss. Nt J Prev Med 2012;3(1):s42

7. Simhachalam Reddy N. Edentulism-An Epidemiological Survey of Population in Chennai, India. J Orofac Sci, 2010;2(1):14-18.

8. Porta M. A dictionary of epidemiology fifth ed. Am J Epidemiol 2009;170(11):1449-1451.

9. Eklund SA et al. Risk factors for total tooth loss in US. J Public Health Dent 1994;54:5-14

10. Hongal S et al. Ann Med Health Sci Res An evaluation of dental prosthetic status and prosthetic needs among eunuchs (transgenders) residing in Bhopal city, MP, Indian-a cs study 2014;4(6):943-8. 